\title{
REVIEW
}

\section{Life-history plasticity in female threespine stickleback}

\author{
JA Baker ${ }^{1}$, MA Wund ${ }^{2}$, DC Heins ${ }^{3}$, RW King ${ }^{1}$, ML Reyes $^{1}$ and SA Foster ${ }^{1}$
}

The postglacial adaptive radiation of the threespine stickleback fish (Gasterosteus aculeatus) has been widely used to investigate the roles of both adaptive evolution and plasticity in behavioral and morphological divergence from the ancestral condition represented by present-day oceanic stickleback. These phenotypes tend to exhibit high levels of ecotypic differentiation. Population divergence in life history has also been well studied, but in contrast to behavior and morphology, the extent and importance of plasticity has been much less well studied. In this review, we summarize what is known about life-history plasticity in female threespine stickleback, considering four traits intimately associated with reproductive output: age/size at maturation, level of reproductive effort, egg size and clutch size. We envision life-history plasticity in an iterative, ontogenetic framework, in which females may express plasticity repeatedly across each of several time frames. We contrast the results of laboratory and field studies because, for most traits, these approaches give somewhat different answers. We provide ideas on what the cues might be for observed plasticity in each trait and, when possible, we inquire about the relative costs and benefits to expressed plasticity. We end with an example of how we think plasticity may play out in stickleback life history given what we know of plasticity in the ancestor.

Heredity (2015) 115, 322-334; doi:10.1038/hdy.2015.65; published online 19 August 2015

\section{INTRODUCTION}

Life-history traits are those features of organisms that are directly and intimately connected to reproductive output. Although life-history traits may have low average heritability, they typically possess sufficient additive genetic variation to respond rapidly to selection (Mousseau and Roff, 1987). In addition, life-history traits commonly exhibit substantial plasticity (Mousseau and Fox, 1998; Nylin and Gotthard, 1998). This ability to respond to environmental challenges via rapid evolution, plasticity or both may be a hallmark of life-history traits. Individual life-history traits are integrated within a complex network of positive and negative (tradeoff) relationships not just among themselves (Stearns, 1989; Roff, 1992), but also with many other aspects of the phenotype (Forsman, 2014). This complexity places limits on the extent to which individual traits can shift plastically and still cumulatively produce the maximum reproductive fitness (Brown and Shine, 2007; Hamel et al., 2014). This complexity is particularly important for female animals because of the large per-offspring investment that females make.

Core reproductive life-history traits in female animals commonly include the age (or size) at maturation, the level of reproductive effort, egg or offspring size, clutch size (eggs or offspring produced during one relatively short period of reproduction) and reproductive frequency (Reznick et al., 2000). Growth rate is sometimes considered to be a life-history trait (see, for example, Arendt, 1997). However, in this review we differentiate it from those traits listed above because although growth rate contributes to reproductive potential (for example, by potentially increasing size at each reproductive event), it is involved as an outside influence on the set of traits we consider (see 'Initiation of Maturation' section below). In iteroparous animals, these female traits may be considered to be developmentally inducible, although not in the usual ontogenetic sense. Rather, they represent iteratively inducible traits that are expressed repeatedly throughout the life of the organism (Foster et al., 2015). Even the most rapid plastic responses in female life-history traits cannot be considered activational (sensu Snell-Rood, 2013), a common characteristic of behavioral traits. Nevertheless, life-history plasticity may be expressed at several very different timescales-from clutch-to-clutch adjustments (Kolm, 2001; Vrtilek and Reichard, 2014), to a gradual adjustment in reproductive traits as the breeding season approaches (Kennedy et al., 2008), to year-to-year shifts (Lee et al., 2012) and across generations via maternal effects (Bashey, 2006; Galloway and Etterson, 2009).

Most trait expression probably comprises a mixture of constitutive and plastic components (Grimaldi et al., 2005; Bourdeau, 2012). With respect to life history, all normal females express a set of traits associated with reproduction - a nonzero level of reproductive effort, egg or offspring size, clutch or brood size; and frequency of reproduction. In this respect, these are constitutive traits, and each female presumably has some genetically determined level of expression based on allelic variation associated with the individual traits. In many species, life-history traits also show considerable inducible plasticityadjustments to the constitutive expression made in response to an environmental cue. Trait expression, achieved by whatever mechanism, is presumably optimized as part of the overall phenotype (Lancaster et al., 2010).

In this paper, we review data for the threespine stickleback (Gasterosteus aculeatus), and our use of the word 'stickleback' for brevity refers to that species only. However, much of what we conclude may apply to other stickleback species, and even many

${ }^{1}$ Department of Biology, Clark University, Worcester, MA, USA; ${ }^{2}$ Department of Biology, The College of New Jersey, Ewing, NJ, USA and ${ }^{3}$ Department of Ecology and Evolutionary Biology, Tulane University, New Orleans, LA, USA

Correspondence: Professor JA Baker, Department of Biology, Clark University, 950 Main Street, Worcester, MA 01610, USA.

E-mail: jbaker@clarku.edu

Received 7 December 2014; revised 20 April 2015; accepted 22 April 2015; published online 19 August 2015 
other teleosts. As we demonstrate, life-history traits of female stickleback show varying degrees of apparent plasticity. The likelihood that plasticity will evolve in a particular trait depends on several factors, one of which is the response time between exposure to a cue and the expression of an appropriate response (Moran, 1992; Padilla and Adolph, 1996). Thus, female stickleback life-history traits may require different cues with different lag times before expression of the phenotype (DeWitt et al., 1998). The reliability of the cue is also important (DeWitt and Scheiner, 2004). The relative costs and benefits of plasticity in individual traits may differ, and this may also contribute to differences in levels of plasticity (Relyea, 2002; Koivula et al., 2003). Finally, traits are linked both genetically and functionally, and thus expressed plasticity in one trait would seem to require simultaneous plastic expression in at least one other trait, and perhaps more. In such cases, we may discover a hierarchy of trait plasticity that reflects the relative importance of each trait in determining fitness.

The threespine stickleback adaptive radiation has proven a model for understanding evolutionary processes in general (Bell and Foster, 1994), and for investigating behavioral (Foster and Wund, 2011; Foster et al., 2015) and morphological (Wund et al., 2008, 2012) plasticity specifically. In contrast, there has been much less discussion of life-history plasticity in this model species. In this paper we seek to summarize what we do know, and hopefully prompt researchers to take fuller advantage of this easily studied species. For each core reproductive trait noted earlier we provide a brief general overview of plasticity in the trait, highlighting studies of fish where possible. This is not a comprehensive review of plasticity per se, and hence the studies we highlight are illustrative only; we minimize the number of references for brevity. We indicate what we understand about plasticity of each trait in stickleback, and the evidence that supports our inference. We attempt to identify the cue that females use to adaptively adjust trait expression, the reliability of the cue and the likely time lag in response. In the last section we speculate on how plasticity may operate within the overall life history of threespine stickleback, discussing possible constraints, and costs and benefits where possible.

\section{THE THREESPINE STICKLEBACK ADAPTIVE RADIATION}

$G$. aculeatus comprises a very large complex of differentiated populations including a number of clear, but unnamed biological species (Bell and Foster, 1994; McKinnon and Rundle, 2002). The complex is broadly distributed in marine, brackish and coastal fresh waters in boreal and temperate regions of the northern hemisphere, encompassing fully marine, estuarine, anadromous and freshwater lifestyles. Freshwater populations in northern regions covered by ice during the last glacial maximum must have been colonized in the past 12000 years (Reger and Pinney, 1996), whereas populations in unglaciated regions can be much older (Oravec and Reimchen, 2013). Freshwater populations in postglacial regions have generally been shown to display pronounced parallelism in the divergence of behavior and morphology among populations in response to foraging opportunities ('benthic-limnetic continuum': Foster et al., 1998; Rundle et al., 2000), and to differences in predation levels (Messler et al., 2007) that can offer significant insights into the adaptive value of particular phenotypes (Schluter, 2000). The impressive levels of parallelism in morphology and behavior appear not to be mirrored in the patterns of differentiation of female life-history attributes (Baker et al., 1998, 2005, 2008).

A second attribute of the threespine stickleback adaptive radiation that is unusual, and of value with respect to understanding evolutionary pattern, is the continued existence of oceanic stickleback, considered to be reasonable surrogates for the ancestors that gave rise to the postglacial freshwater radiation within regions (see, for example, Hohenloe et al., 2012; Foster, 2013). This attribute of the radiation permits inference of the direction of evolutionary transitions, and allows us to ask questions about the patterns of evolutionary change in population contrasts.

\section{INITIATION OF MATURATION}

The size or age at which an organism begins to divert resources to reproduction is a critical life-history trait (Henderson and Morgan, 2002; Barot et al., 2004). This may be especially important when breeding opportunities are limited, as in semelparous fish (Crespi and Teo, 2002), in monocarpic plants (Burd et al., 2006) and in short-lived organisms such as threespine stickleback (Baker et al., 2008) and guppies (Reznick et al., 1990). Plasticity for size/age at reproduction has been extensively modeled (Berrigan and Koella, 1994; Marty et al., 2011), comprehensively reviewed recently in insects (Teder et al., 2014) and has been demonstrated in a wide array of fish species (Morita and Fukuwaka, 2006; Hutchings and Jones, 2008). Early-life reproduction is likely to be particularly important in short-lived species living in strongly seasonal environments that constrain breeding to a short period of the year (Adolph and Porter, 1996; Merila et al., 2000). Except for obligate annual species, the age at which an organism matures is almost always plastic (Day and Rowe, 2002). In long-lived iteroparous organisms, this maturation plasticity may permit the organism to skip reproductive events entirely (Rideout et al., 2005; Skjæraasen et al., 2012). Some of the established determinants of the expression of plasticity for maturity in fishes include early-life growth rate (Bertechy and Fox, 1999; Copp and Fox, 2007), size (Teder et al., 2014) and energetic status (for example, lipid content; Thorpe, 2007).

Females in most threespine stickleback populations can expect to breed in only 1-2 seasons (Baker et al., 2008; but see Oravec and Reimchen, 2013), even though in many populations older females are often present. Seasonal constraints on the timing of the reproductive period in most populations mean that if a female does not breed at age 1, she must wait an entire year. Early reproduction, on average, produces a higher intrinsic rate of increase because of reproductive 'compounding' (Roff, 2000; Anguilletta et al., 2004), and thus selection should favor plasticity because of the high value of reproducing at an early age when it is profitable. Age and/or size at first breeding has been shown to have a heritable basis in stickleback (McPhail, 1977; Snyder and Dingle, 1989; Snyder, 1991), but several lines of evidence strongly suggest that it is plastic as well. We have studied more than 130 freshwater populations over the past 20 years in Alaska and southern British Columbia. In virtually all of these populations, a (variable) proportion of first-year females is included in the breeding pool in the wild (Figure 1). Although this could result from populations consisting of a mixture of females that are genetically determined to breed at either age 1 or age 2, and then die, the most likely explanation is that females exhibit plasticity for initial age of breeding. Such plasticity was nicely documented by Saito and Nakano (1999) who demonstrated that females in one population bred either at age 2 or age 3, depending upon the size they reached in the previous year. We have raised more than 30 populations in the laboratory, and have found that most females can become reproductive (given appropriate light cues) at age 1 , even in populations where age-1 breeders are uncommon in nature (for example, Walby Lake; Heins et al., 2010). Furthermore, in the laboratory, the fish that fail to breed at age 1 are nearly always unusually small individuals. These results must be viewed with some caution, as our laboratory-reared fish typically receive maximum rations throughout their first year of life, 

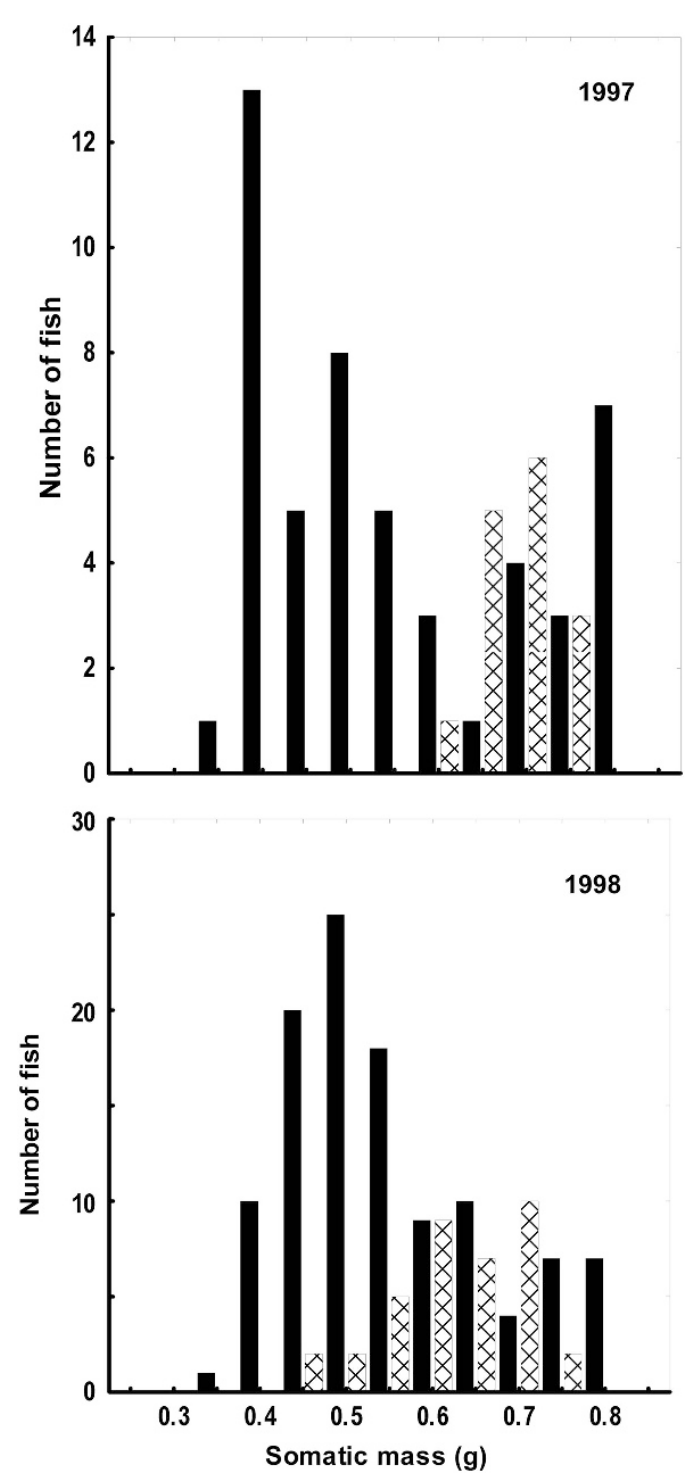

Figure 1 Size frequency of age-1 female threespine stickleback in Cornelius Lake, Alaska. Solid bars indicate nonbreeding females, confirmed by dissection; hatched bars indicate females that were in the clutch-production cycle (Baker et al., 1998). Breeders are clearly primarily the larger fish, although size is not a perfect predictor, as some larger fish are not breeders. The main group of breeding females in this population are age- 2 individuals.

and this may not be typical. Finally, Snyder (1991) showed that stickleback could become reproductive as early as 195-220 days of age, given sufficient growth and appropriate environmental cues.

In the wild, female oceanic stickleback in Alaska breed primarily at age 2 (Baker et al., 1998, 2008; Karve et al., 2013; RW King, unpublished data). Narver (1969) suggested that the 'estuarine' population in Chignik Lagoon, Alaska, bred at age 1; however, the sizes of fish reported in that study $(65-90 \mathrm{~mm})$ are clearly age 2 based on our extensive spatial and temporal sampling of ancestral populations in Alaska. Presumably, age-1 fish were not present on the breeding grounds where Narver (1969) collected. Despite generally breeding at age 2, a small and annually variable proportion of age-1 Alaska fish do breed (Figure 2). In British Columbia (JA Baker, unpublished data) and the St Lawrence River estuary (Picard et al., 1990), breeders are also a variable mix of age-1 and age-2 fish. As with freshwater stickleback, oceanic stickleback reared in the laboratory (six populations from Alaska and three from British Columbia) all show a very high probability of reproducing at age 1 . These multiple lines of evidence suggest that plasticity is the ancestral condition. In most freshwater populations we observe at least two age classes of breeding females, suggesting that many females can reproduce in multiple years, as they do in the laboratory. Females from both ancestral and freshwater populations that reproduce in the laboratory at age 1 show a high probability of surviving to age 2 and breeding the following year.

The cue initiating maturation is probably an aspect of the maternal phenotype itself (Metcalfe and Monaghan, 2003), such as body size (Weeks and Quattro, 1991; Saito and Nakano, 1999) or energy state (Morgan, 2004; Vitousek et al., 2010). Our current work (ML Reyes and JA Baker, unpublished data) suggests that size may be the most important variable cueing reproduction at age 1 in stickleback, as fish encountering a period of low rations late in their first growing season recover size instead of lipid stores if ration is increased (Figure 3). This also corresponds with the observation that size is the best predictor of female reproductive output per clutch (Wootton, 1973a; Wootton, 1977; Ali and Wootton, 1999a; Baker et al., 2008), with energy state or current ration level having smaller effects (Ali and Wootton, 1999a) or no detectable effect at all.

Experiments (Wootton, 1973b; Inness and Metcalfe, 2008) show that high rations increased the proportion of female stickleback that matured at age 1, and that size is probably the best indicator of the probability of maturing. Subsequently, Ali and Wootton (1999b) found that breeding and nonbreeding first-year females did not differ in average size, but they collected their fish from the wild in 'midwinter', when females may have already made a decision to mature or not. Females begin mobilizing energy into ovarian and support tissue in winter (Wootton et al., 1978, 1980; Wootton, 1994; Sokolowska and Kulczykowska, 2006), indicating that a response (mature, or not) may be determined several months before the reproductive season begins. This suggests that the cue is likely to be highly reliable, because reproducing when size or energy is insufficient likely leads to low survival to age 2 (see, for example, Vitousek et al., 2010), and failing to breed when size or energy is sufficient surrenders the compounding advantage of early reproduction.

Reproduction at age 1 would be favored if it resulted in a lifetime reproductive output exceeding that of females that delayed breeding to age 2 (Roff, 2002). Because female size has the greatest influence on clutch size, reproduction at age 1 should be favored only when it does not substantially diminish survival to, or size at, age 2 (Hutchings, 1999). The enormous reproductive effort made by female stickleback prevents most individuals from growing substantially during the reproductive season (Wootton et al., 1978). However, in Alaska, breeding ends by mid-July in most populations (Heins et al., 1999), providing females up to 3 months of growth before the next winter. This suggests that females of sufficient size and energy state that breed at age 1 will be able to offset some of the growth cost of reproduction, and will attain the highest lifetime output of potential offspring, whereas smaller and/or less energetic females may do better by waiting until age 2, favoring plasticity for this trait. This is the explanation for the alternating reproductive age pattern observed by Saito and Nakano (1999), in which seasonally late-hatched fish did not achieve the minimum reproductive size until age 3 , whereas early hatched fish grew large enough to reproduce at age 2. 


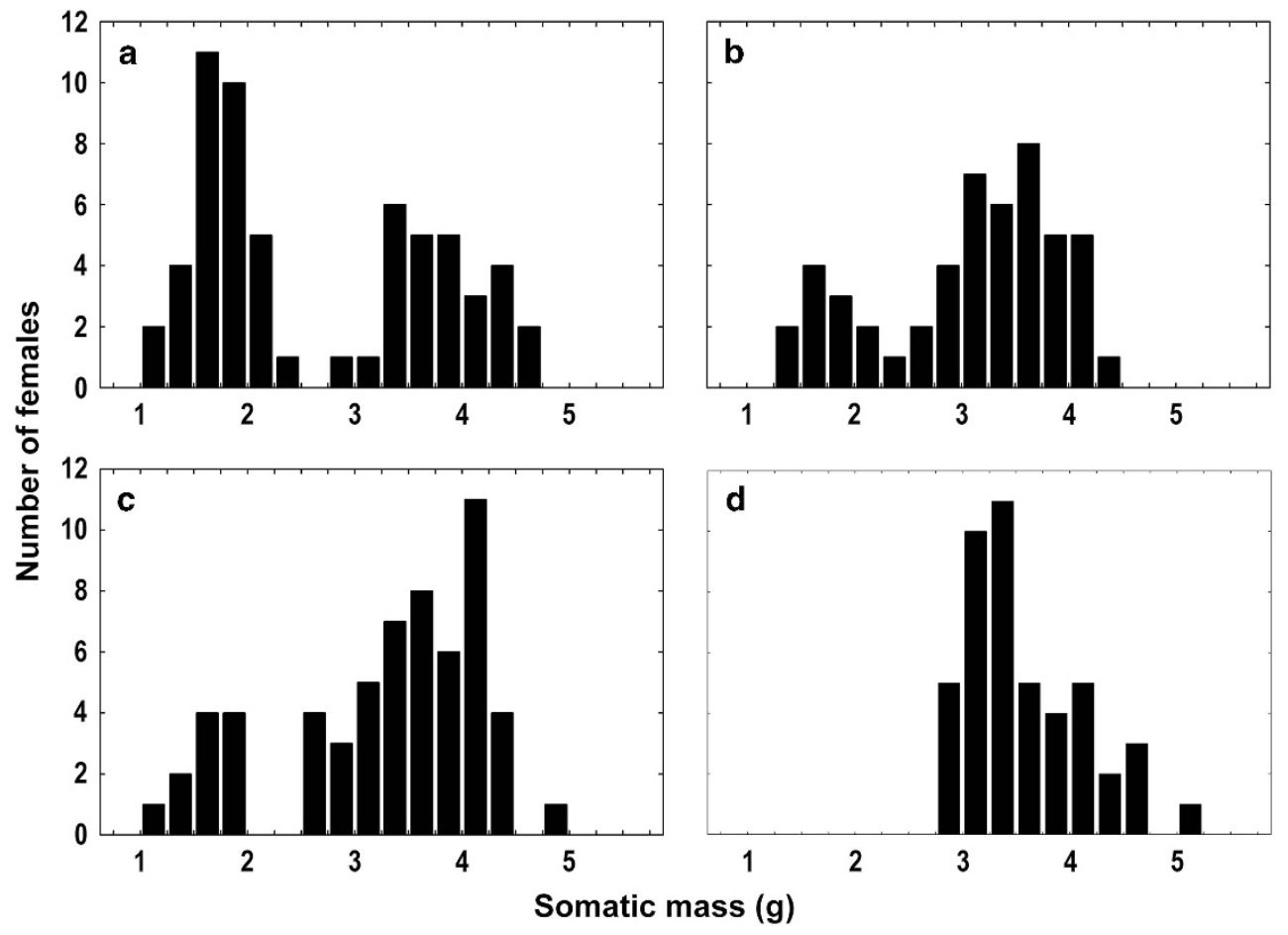

Figure 2 Size frequency of anadromous threespine stickleback on the breeding ground in two Alaskan populations. (a-c) Anchor River population 1995-1997. (d) Mud Lake population (Karve et al., 2013). All fish are reproductive females captured on the breeding grounds. The clear size modes in Anchor River represent age-1 and age-2 breeders; only age-2 breeders make the extended migration up the Knik River system and tributaries to spawn in Mud Lake.
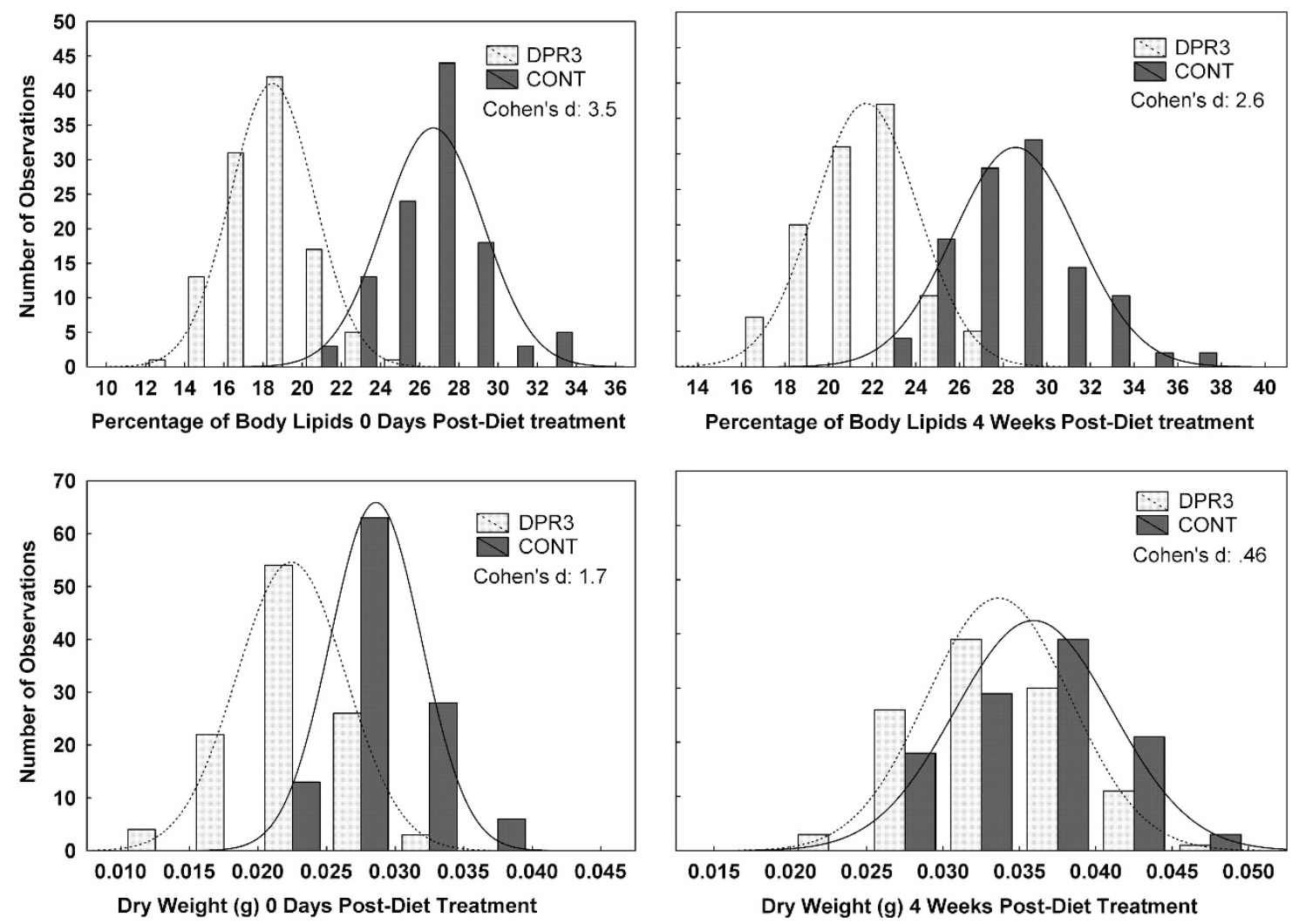

Figure 3 Comparison of compensatory responses in somatic mass and lipid content of threespine stickleback in experimental (DPR3) and control (CONT) fish that experienced a $50 \%$ reduction in ration in their fourth month of life ( 2 months before over-wintering). The left panels show values at the end of 1 month of reduced ration; the right panels show values after a return to full ration for 1 month. The magnitude of the differences between control and experimental fish for each panel is indicated by an effect size metric (Cohen's $d$ ). 


\section{REPRODUCTIVE EFFORT}

The relationship between current and future performance is manifested in one of the principal tradeoffs shaping life-history evolutionthe 'cost of reproduction' (Reznick et al., 2000; Kuparinen et al., 2011). The level of effort put toward reproduction can affect the probability of survival (Gunderson, 1997; Moore and Attisano, 2011), future reproduction via reduced growth (Roff, 2000; Tsiklris et al., 2007) or both (Koivula et al., 2003), depending upon environmental conditions (Shine, 1980; Hamel et al., 2014). Plasticity in level of reproductive effort has been documented in a variety of ectotherms, including insects (review in Nylin and Gotthard, 1998), fish (Pampoulie et al., 2000; Kolm, 2001), snakes (Brown and Shine, 2007) and marine iguanas (Vitousek et al., 2010). In animals, plastic expression can range from clutch-to-clutch adjustments (Wisenden, 1993) to the sudden abandonment of reproduction and resorption of eggs (Vitousek et al., 2010; Moore and Attisano, 2011). In some fish, annual opportunities for spawning may be skipped (Trippel and Harvey, 1989; Skjæeraasen et al., 2012). In iteroparous organisms like the threespine stickleback, which are capable of producing multiple clutches in multiple years, plasticity of reproductive effort may exist at three levels: (1) within years across sequential clutches, (2) within years for the number of clutches and (3) across years. These could represent different plastic response mechanisms or different manifestations of a single plastic mechanism.

The mass of the eggs spawned in a single clutch is a common proxy for the relative amount of energy devoted to reproduction by a female during the time interval required to produce the clutch (Roff, 2002). Scaled to female body mass, this metric constitutes one of the most widely used indices of reproductive effort (gonadosomatic index: Gunderson and Dygert, 1988; relative clutch mass; Heins and Baker, 1993). On this basis, threespine stickleback make a relatively large effort per clutch. Averaged over 83 populations, Alaskan stickleback produce clutches that weigh more than one-fourth the somatic weight of the female (mean $=26.6 \%$, Figure 1 in Baker et al., 2008), and oceanic females produce clutches that weigh $>36 \%$ their body weight (Baker et al., 1998). Similar values were observed for stickleback from British Columbia (Baker et al., 2013; JA Baker, unpublished data). Wootton and Fletcher (2009) reported values of $\sim 16 \%$ for their highest ration; however, they used a different measure of female mass in their calculations. An approximate adjustment indicates that their values are similar, or only slightly lower, than ours.

Reproductive effort can also be evaluated over an entire season by incorporating the frequency of clutch production. Our data for multiple laboratory-reared populations, and that of Wootton for Welsh populations (Wootton, 1973b; Wootton and Fletcher, 2009) show that healthy, well-fed females can produce 8-9 clutches, and occasionally more, at intervals of 3-9 days within a season, producing up to 1000 eggs before ceasing reproduction (see also Brown-Peterson and Heins, 2009). Thus, a female stickleback may produce eggs that represent 1.4 times (Wootton and Fletcher, 2009) to 2.25 times (JA Baker, personal observation) and to possibly 3-4 times her somatic mass in one season (Wootton, 1973b). The careful experiments of Wootton, 1973b) indicated that larger and better fed females produced more clutches, but not larger relative clutch masses (scaled for body size). This effect has been reported in other species (Donelson et al., 2008; Hamel et al., 2009). Similarly, Hooker (1988) reported in an experimental study of two stream stickleback populations from extreme southwestern British Columbia that females could produce up to 9 clutches per season, and a maximum total of about 850 eggs. However, interclutch intervals ranged more widely (10-30 days), and Hooker (1988) found that smaller females actually produced more

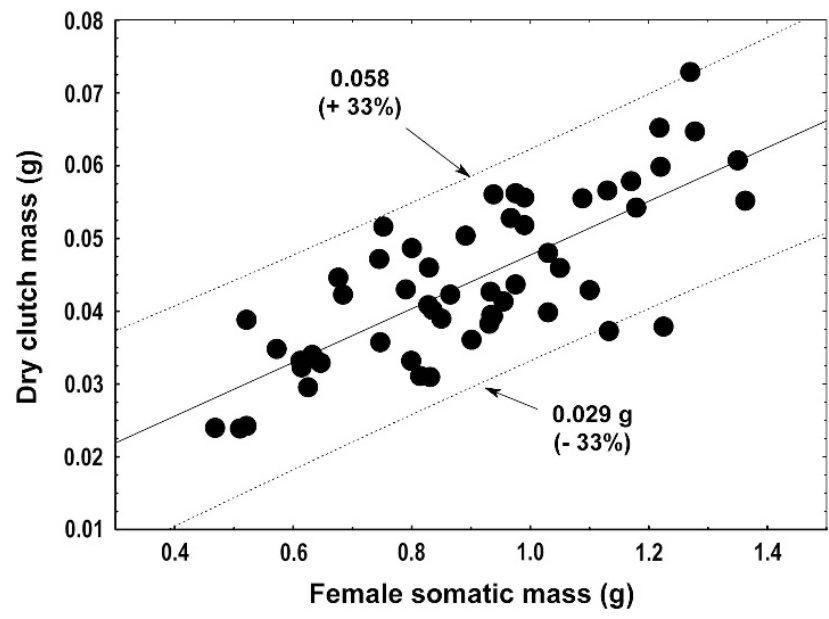

Figure 4 The relationship between dry clutch mass (an indicator of reproductive effort) and female somatic mass in Big Beaver Lake, Alaska, 1997. Each symbol indicates an individual female. At the mean somatic mass of $0.90 \mathrm{~g}$, female clutch mass can vary higher or lower by as much as one-third from the expected value along the regression line.

clutches, so that seasonal fecundity was almost independent of female size.

The balance of experimental evidence thus suggests that clutch-toclutch plasticity in reproductive effort in threespine stickleback is limited, and that females may generally reproduce near the maximum level for their body size and energy state. These conclusions are also consistent with the finding that the average level of reproductive effort per clutch across stickleback populations closely tracks average body size (Baker et al., 2008). Nevertheless, there is often substantial individual variation in the clutch mass to body mass ratio among wild-caught females (Figure 4) that is difficult to reconcile with the experimental studies of Wootton, 1973b). Field data suggest that, as the breeding season nears, individual females integrate cues from their current state (body size, lipid stores, liver glycogen level) and ration level to set the level of per-clutch reproductive effort for that season (Vitousek et al., 2010) that, under certain circumstances, may result in considerable individual variation about the population effort-size trajectory. At present, we do not know how much of this variation is due to constitutive (allelic variation) or plastic effects.

Reproductive effort in fish tends to remain fairly consistent throughout a reproductive season (examples in Vrtilek and Reichard, 2014), and therefore within-season plasticity of reproductive effort may be mediated primarily via the number of clutches in many cases. Studies by Ali and Wootton (1999a) and Wootton and Fletcher (2009) show that once stickleback females begin reproducing, they maintain their initial strategy of making a size-appropriate clutch mass regardless of subsequent changes in ration levels. In contrast, interclutch interval is sensitive to ration, lengthening under low rations. This plasticity for interclutch interval may simply be a nonadaptive response to resource reduction. However, it may also indicate adaptive plasticity if the resources required to maintain the original interclutch interval would result in a somatic cost (for example, poorer condition or immune system function), leading to a lower survival probability.

Our evidence for substantial plasticity for reproductive effort also includes comparisons of many populations assayed in the wild and raised in a common laboratory environment. In the presumably benign laboratory environment, effort is typically lower per clutch for 
a

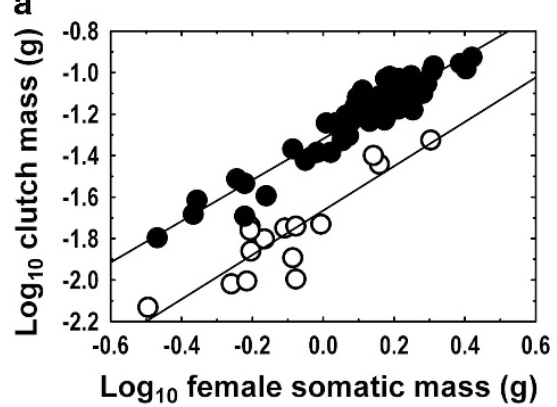

b

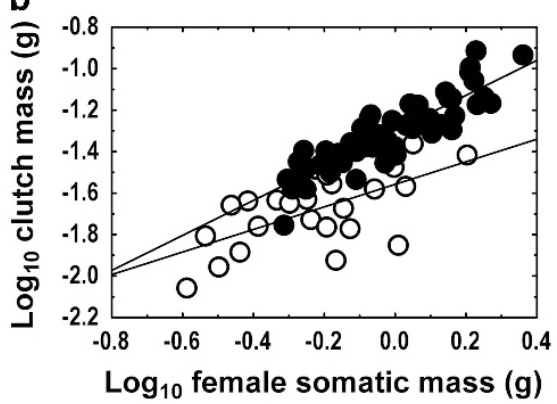

d

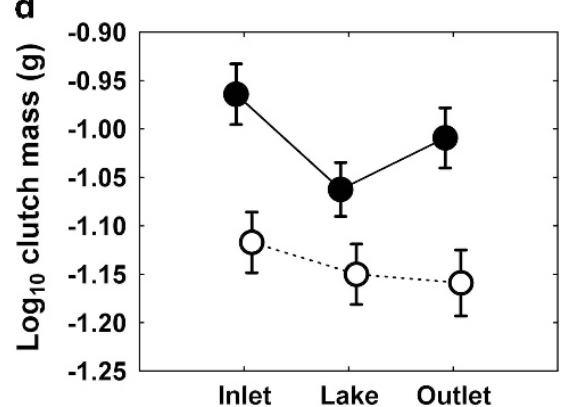

Figure 5 Relationships between clutch mass and body mass in female threespine stickleback from four populations studied in the wild (solid circles) and in the lab (open circles). (a) Lynne Lake, Alaska—limnetic body shape. (b) Cornelius Lake, Alaska—intermediate body shape. (c) Willow Lake, Alaska—benthic body shape. (d) Shown are clutch masses for stickleback from three distinct habitats within the Misty Lake ecosystem, British Columbia, adjusted to a common female mass of $2.45 \mathrm{~g}$. In panels a-c, fish less than $\sim 1 \mathrm{~g}$ are age 1 individuals.

first-year females than in the field (Figure 5; Baker et al., 2013). Oceanic and estuarine populations, in which the majority of females appear to breed in just 1 year, with few lifetime clutches (Narver, 1969; Crivelli and Britton, 1987; Boulé and FitzGerald, 1989), show a relatively small change compared with freshwater populations. Freshwater populations can produce many clutches in a single breeding season (Wootton, 1973b; Wootton and Evans, 1976; Copp et al., 2002; Wootton and Fletcher, 2009), and probably in more than a single year in many populations (Baker et al., 2008; Lee et al., 2012). The smaller reduction by ancestral stickleback in the laboratory suggests that more limited plasticity of reproductive effort is the ancestral condition. Reproductive effort also appears to be reduced with length of migration in anadromous stickleback in Alaska (Karve et al., 2013; JA Baker, personal observation), but at present we do not know whether this represents plasticity or population-specific adaptive variation.

The energetic needs of reproduction may be met in two waysstored energy or energy consumed as reproduction proceeds, corresponding to the ends of a continuum from capital to income breeding (Houston et al., 2007; Stephens et al., 2009). It is likely that stickleback fall somewhere between these extremes because even fed maximum rations (16\% body weight per day: Wootton and Fletcher, 2009), stickleback reproductive effort declines over a spawning season. Stickleback might express adaptive plasticity for this trait as well (as do aspic vipers; Lourdais et al., 2002). Stickleback emerge from a 5-6month winter in early May in Alaska, and have 0.5-1.0 months to regenerate lipid stores and liver glycogen for reproduction. Thus, depending on their energy state emerging from the winter, and earlyseason food quantity, females may enter the reproductive period with varying levels of reproductive capital that then may cue plastic adjustments in traits that depend critically on energy flow for reproduction (Madsen and Shine, 1999; Casas et al., 2005).
A plausible explanation for the difference between data derived from experimental versus wild-caught populations is that Wootton worked with largely annual populations (for example, Wootton and Fletcher, 2009), whereas our data come mostly from populations in which females may reproduce over 2-3 years. Annual versus longerlived populations might be anticipated to evolve differently with regard to the expression of plasticity in reproductive effort, and indeed probably in most traits. Thus, our data suggest that stickleback may exhibit more substantive plasticity, by setting an appropriate level of reproductive effort before the breeding season-even though they do not change that effort throughout a season.

Stickleback that can breed in more than a single season also often display season-to-season plasticity in level of effort, expressed ontogenetically as an increasing commitment to reproduction as they age. That is, allometric slopes (model II, reflecting error in both $x$ and $y$ variables) relating clutch mass to body mass are $>1$ in many populations we have studied (Figure 6). Such an increase is expected under lifetime allocation models of reproductive effort (Roff, 2002), and thus represents adaptive plasticity. All of our data bearing on this phenomenon are from cross-sectional studies of females of multiple ages collected at one time, and we know of only one study (Lee et al., 2012) that has tracked individual stickleback across multiple years. However, numerous experiments by Wootton cited above suggest that the population-level trends relating reproductive effort to body size/ age may mirror those of the individual females themselves. This form of plasticity should be expressed even within a breeding season in annual populations, and indeed this was observed by Poizat et al. (1999) in the Camargue estuary, southern France. These data suggest that plastic adjustments to reproductive effort between years is adaptive, most likely because lower than maximum levels of reproduction at young ages can enhance survival to one or more subsequent breeding years (minimize survival cost; Bertschy and Fox, 1999) in most freshwater populations. The energy state of the female, perhaps 

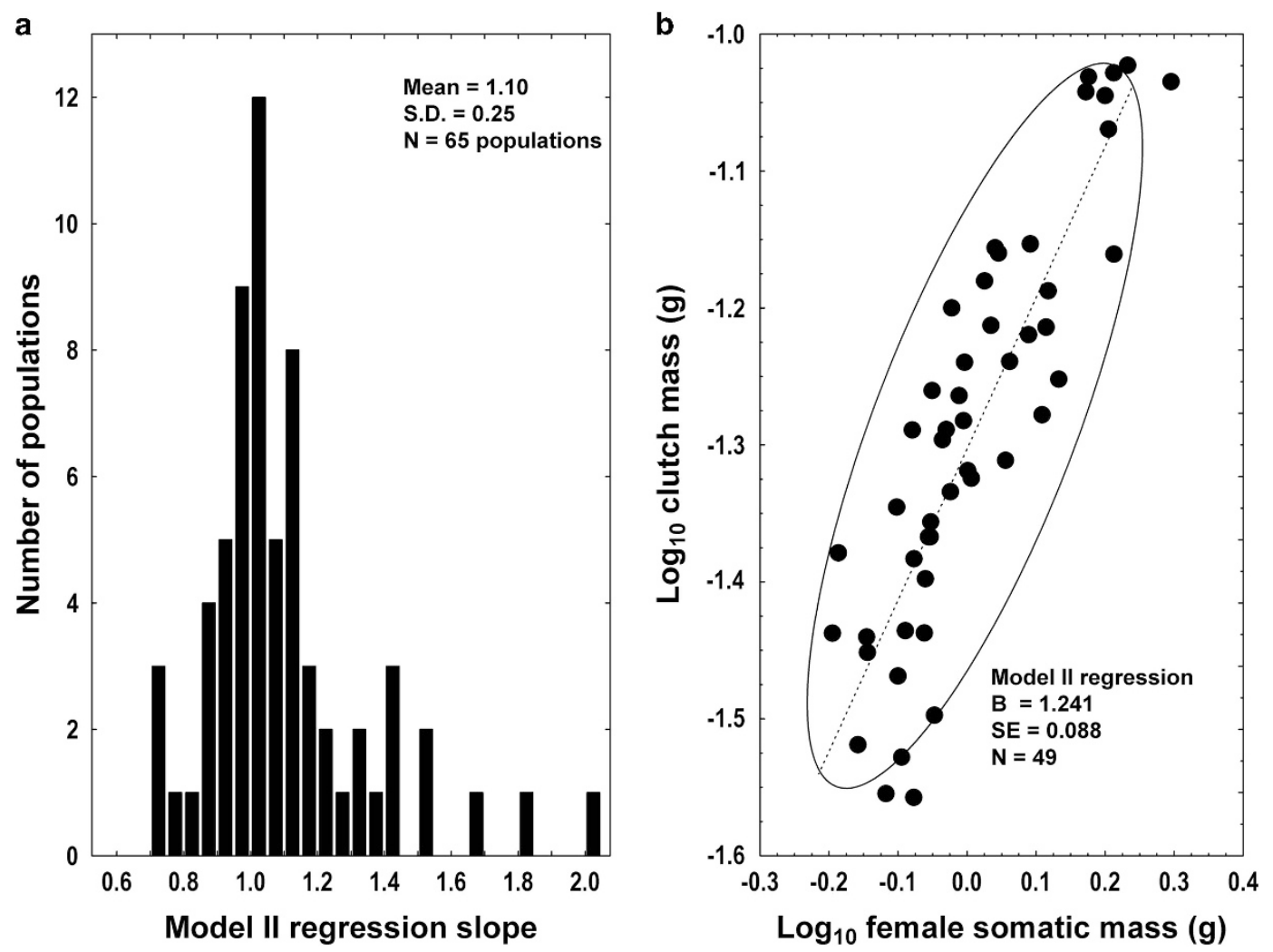

Figure 6 (a) The distribution of population-level regression slopes (model II) for 65 Alaskan populations of threespine stickleback. A slope of $>1$ indicates that relative reproductive effort increases with size/age. (b) An example of a one population's relationship; each filled circle represents an individual female. A $99 \%$ bivariate probability ellipse is fitted to the data, with the model II regression trend indicated by a dashed line.

in combination with current income, may be a cue to adjust the overall level of reproductive effort to maximize survival to older ages, at least in populations where older females commonly breed. In contrast, older females may commit greater resources to reproduction as they have reduced probability of breeding in future years.

Body size is the best predictor of clutch size in stickleback (Fletcher and Wootton, 1995; JA Baker, personal observation), and a population's clutch mass to body mass regression trend may approximate the constitutive expression of reproductive effort across the lifetime (the trajectory). Individual females may have constituently lower or higher efforts at each size, but may generally follow the population trajectory. However, females could adaptively modify this expression by either increasing or decreasing reproductive effort to maximize their expected lifetime output of offspring. The cue is likely to be female energy state, and current feeding conditions, and must act in just a few weeks before first breeding of each season, and thus the lag time between cue and response is relatively short. This is a clear case of iterative developmental plasticity in which females are able to adjust reproductive effort in relation to perceived food availability, individual condition and expectation of future reproductive opportunities.

\section{EGG SIZE}

Offspring size is a critical life-history trait (Bernardo, 1996), and selection on offspring size is often strong. It may be particularly pronounced in fish (Kingsolver et al., 2001), and in which it commonly favors larger size in the youngest fish (Duarte and Alcaraz, 1989; Perez and Munch, 2010). In egg-laying species, an additional complicating feature is that the females produce eggs, and thus the egg-to-offspring mapping must also be taken into account.
Although egg size itself may be under direct selection (Einum and Fleming, 2000b; Simons, 2008), the primary target of selection in most cases appears to be the size and performance of the fry. Thus, there is often found to be a positive correlation between egg size and fry size or capability (Einum and Fleming, 2000a; Segers and Taborsky, 2011). Because even small differences early in life can lead to large variations in fry fitness (Anderson, 1988; Perez and Munch, 2010; JA Baker, unpublished data) plasticity should be a considerable advantage to females. Egg-size plasticity has been well studied, and it is widespread in both egg-laying (Kolm, 2001; Gagliano and McCormick, 2007) and live-bearing (Rodd et al., 1997; Auer, 2010) fish. Complicating the issue is the fact that egg size is a property of both the female and offspring phenotype (Bernardo, 1996), and therefore the best egg size for fry may not be the optimal egg size for females (Einum and Fleming, 2000b). Females may express egg-size plasticity in at least four ways (Marshall and Uller, 2007), three adaptive for themselves and/or the fry (anticipatory, selfish and bet-hedging), and one nonadaptive (transmissive).

Baker and Foster (2002) notwithstanding, egg size appears to show no appreciable short-term adaptive plasticity in stickleback based on experimental manipulation of female diet or condition (Fletcher and Wootton, 1995; Ali and Wootton, 1999b; Inness and Metcalfe, 2008), on comparisons across sequential field collections throughout a breeding season (JA Baker, personal observation) or on sequential clutches when reared in the laboratory (JA Baker, unpublished data). In one population in Wales studied experimentally by Fletcher and Wootton (1995), a significant, positive correlation was observed between egg size and ration size as ration increased from 2 to $16 \%$ body weight per day, suggesting adaptive plasticity with energy income 
as the cue. However, this pattern was entirely generated by a reduced egg size at only the lowest ration, suggesting nonadaptive plasticity instead. Even under such widely varying rations, the lipid-protein ratio of eggs remained unchanged (confirmed by Wootton and Fletcher, 2009), a finding similar to that in Atlantic salmon (Berg et al., 2001), although different from live-bearing guppies (Reznick and Yang, 1993). In addition, unlike reproductive effort, we observed no consistent difference in egg size between lab-raised and wild-caught fish in most populations. Studies show that the cestode parasite Schistocephalus solidus almost always reduces stickleback egg size (Heins and Baker, 2003), and in most populations egg size is inversely related to severity of parasitism, strongly implicating nonadaptive nutrient theft (Heins and Baker, 2008; Heins et al., 2014). However, a recent study found potential adaptive plasticity for egg size in two populations (Heins and Baker, 2014), but in these cases the females have a reliable cue-the parasite within them.

The most plausible explanation for the lack of clutch-to-clutch eggsize plasticity is that females have no reliable cue to guide an appropriate response. The highest mortality rate in most fish populations occurs at the youngest ages (Houde, 1987; Perez and Munch, 2010), and is often attributed to starvation. If so, the cue for provisioning eggs should accurately predict fry feeding environment if the plasticity is to be adaptive. The duration from onset of vitellogenesis to exogenously feeding stickleback fry is at least 14 days at mid-summer Alaska water temperatures (5-6 days to produce a clutch, 6-7 days to hatch and 2-3 days to complete development and begin exogenous feeding), and it is even longer at the cool temperatures experienced early in the breeding season (JA Baker, unpublished data). If female stickleback plastically established a target egg size at the onset of vitellogenesis based on current information on the food availability for fry, this cue would need accurately to predict conditions 2-3 weeks later. Unpredictable variability in weather, competing fry density and temperature make it unlikely that such a cue could be sufficiently accurate.

Despite the apparent lack of short-term plasticity in egg size, approximately half of all freshwater, and all oceanic, populations we have studied exhibit egg-size plasticity between reproductive seasons (iterative ontogenetic plasticity). This is expressed as a positive relationship between egg size and female size or age (Figure 7; Fletcher and Wootton, 1995; Baker et al., 1998, 2008, 2013). This pattern implies that the 'decision' to produce eggs of a particular size might be reset annually, cued by the size, age or energy state of the female when she begins breeding in a particular year, a possibility supported by modeling studies such as those by Kindsvater and Otto (2014). However, this relationship is not displayed in all freshwater populations in Alaska. Because the ancestor displays the relationship, this indicates that some Alaskan populations may no longer express this plasticity. If the cue is indeed internal to the female herself, this could indicate that they have actually lost the ancestral ability to plastically respond. Further evidence of age-related plasticity in egg size is evident from plots comparing clutch size and egg size with female size in one of our long-term study populations (Figure 8). In this population in 1990-1993, females produced body size-appropriate clutches throughout life, but the oldest females appeared to maintain their fecundity by decreasing egg size. It is important to note that this inferred plasticity is based only on cross-sectional studies thus far (females of different sizes and ages within a collection).

\section{CLUTCH SIZE}

Clutch size may be the most fundamental life-history trait, as it represents the maximum number of offspring that can result from a single reproductive event. As a result, the diversity and evolution of clutch sizes have been subjects of intense interest (Godfray et al., 1991). As opposed to reproductive effort, clutch size is relatively easily defined, and relatively easily quantified if done so just before

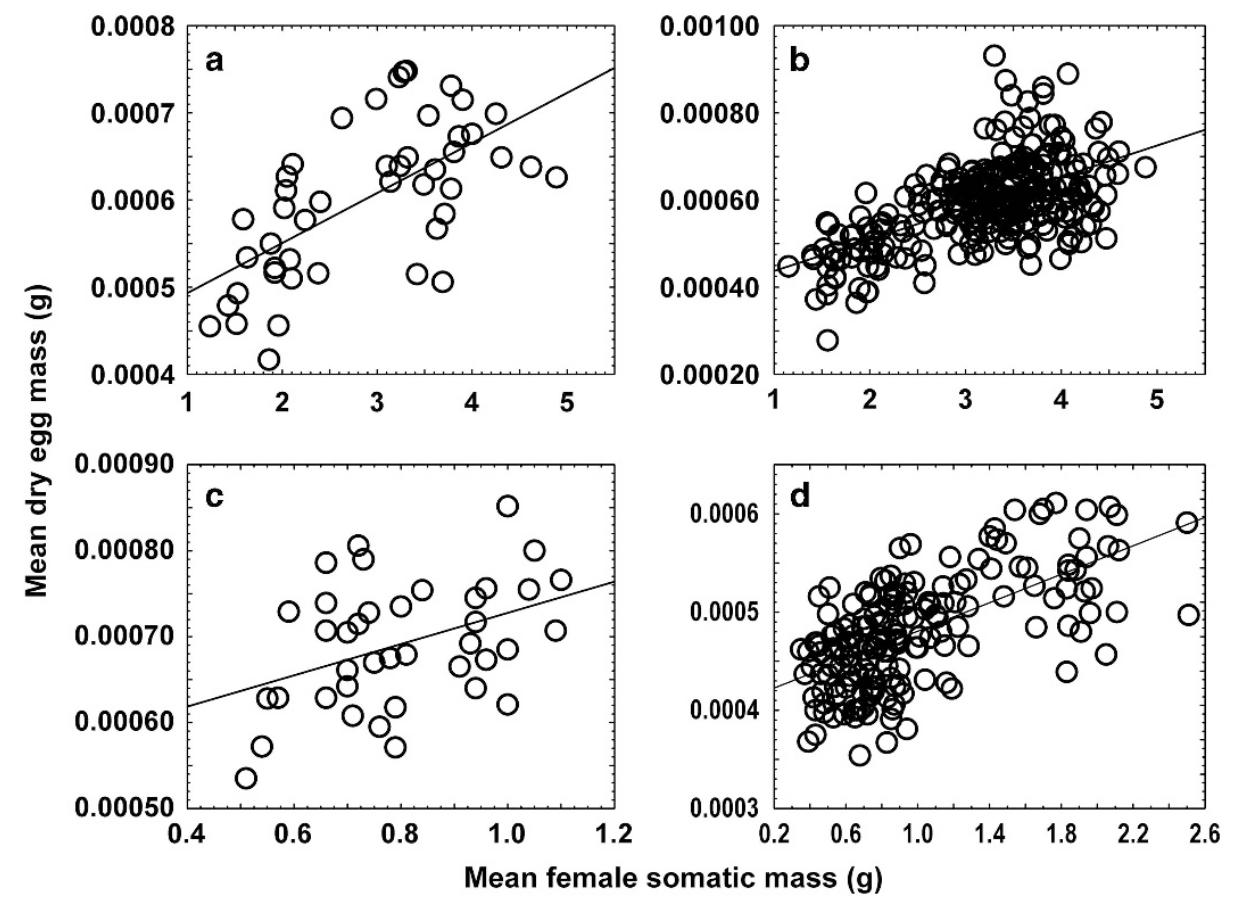

Figure 7 The relationship between egg size (mean dry mass) and female somatic mass (blotted, eviscerated) in four populations of Alaskan threespine stickleback. (a) Resurrection Bay marine; (b) Anchor River anadromous; (c) Daniels Lake fresh water; (d) Bear Paw Lake fresh water. 

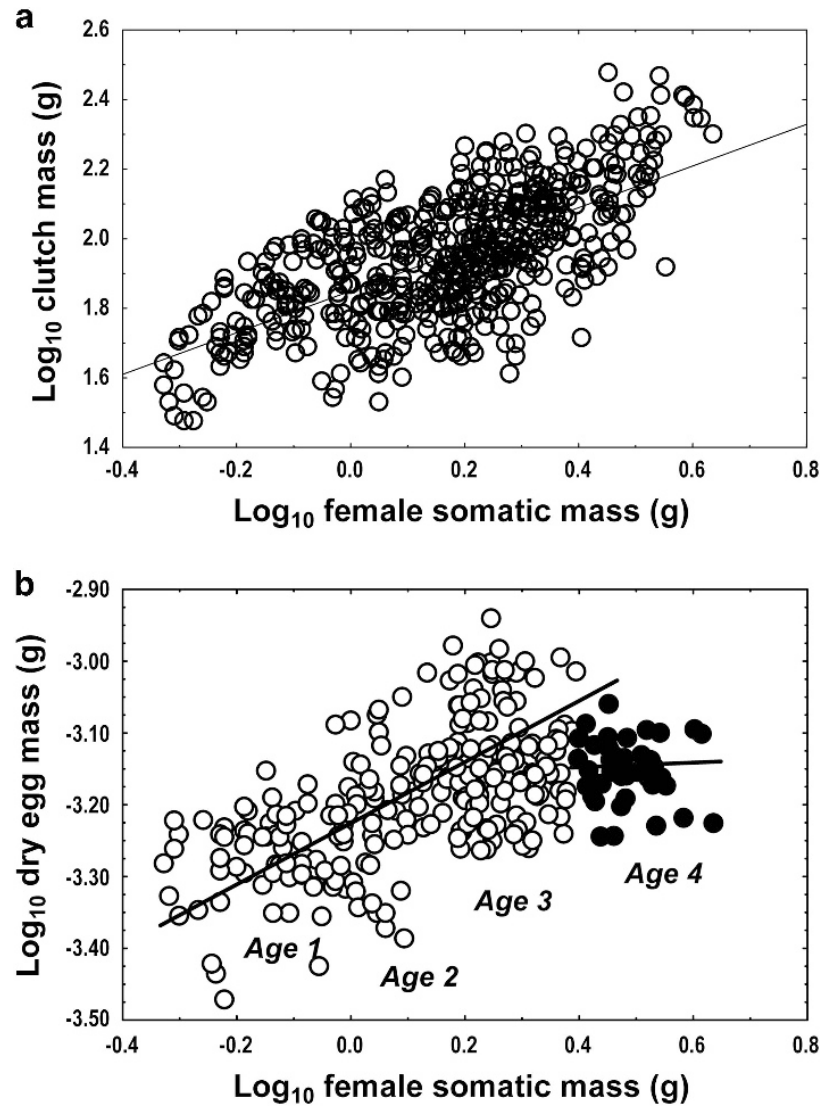

Figure 8 (a) The relationship between clutch size and female body size ( 3 years pooled) in the Solid Rock, Alaska, population. (b) The relationship between egg size and female body size in the same population for the same samples. Note that the oldest females (estimated to be age 4) produce appropriate clutches for their body size, but produce smaller eggs than expected.

reproduction. Plasticity for clutch size has been documented in a wide array of poikilotherms (Roff et al., 1999: Klemetsen et al., 2003), including numerous fish (Kennedy et al., 2008; Evans et al., 2010). Little clutch-to-clutch size fluctuation is reported in ectotherms, but there is evidence for long-term plasticity cued by energy acquisition during the prespawning period when the gonads are developing. In many exploited marine species, for example, downregulation of fecundity is common as the spawning season approaches (Kennedy et al., 2007, 2008, 2009), and is likely an adaptive adjustment of spawning season fecundity to match nutrient levels.

Female stickleback are group-synchronous spawners (Wallace and Selman, 1979), rapidly and synchronously enlarging a clutch of eggs via vitellogenesis and then spawning all quickly in the nest of a single male. This process may be repeated as many as 9 times in a single season in freshwater populations (Wootton and Fletcher, 2009; JA Baker, personal observation), although oceanic populations appear to produce many fewer, though larger, clutches (Boule and FitzGerald, 1989; Dufresne et al., 1990; RW King, personal observation). Clutch size mirrors reproductive effort in threespine stickleback (Baker et al., 1998, 2008; Wootton and Fletcher, 2009), with population-level correlations between these traits ranging from 0.79 to $0.90(N=83$ populations; JA Baker, unpublished data). High correlations between these traits are typical other species as well (Su et al., 1997; Kinnison et al., 2001). As with reproductive effort, clutch size is primarily a function of female size, and under a normal ration does not change appreciably across spawnings (Wootton and Fletcher, 2009; JA Baker, personal observation). Clutch size does show a tradeoff with egg size, once female size effects have been removed (Baker et al., 1998, 2005; Oravec and Reimchen, 2013). Stickleback may not be capable of downregulating clutch size to the extent observed in many marine species, but at present the potential for this to occur is unexplored.

It may be difficult to disentangle the effect of plasticity in reproductive effort from that in clutch size or seasonal fecundity in species like stickleback. Reproductive effort for a female of some specified size can be approximated as clutch size $\times$ egg size. Plastic reductions in reproductive effort would likely be achieved via reductions in the number of follicles recruited into vitellogenesis (assuming no change in egg size) and, as a result, clutch size will decline proportionally to reproductive effort. The data cited earlier for downregulation of fecundity in many marine fishes could thus represent plasticity for level of reproductive effort instead. The distinction is important because traditional life-history theory distinguishes reproductive effort, clutch size and egg size as linked traits, but individually free to respond to natural selection (Jorgensen et al., 2011; but see Winkler and Wallin, 1987).

\section{PLASTICITY WITHIN AN OVERALL LIFE HISTORY}

In this last section, we try to provide an illustration of how multivariate plasticity might play out within the life history of a fish like the threespine stickleback. For brevity and simplicity, we confine ourselves to events that might occur during the reproductive portion of the lifespan, although it is clear that events earlier in life may change how the reproductive portion of the life history plays out (Lee et al., 2012). Plasticity for egg or offspring size is one of the most widely reported aspects of fish life histories, and here we use it as a central trait to explore how multivariate life histories may evolve. We first examine the effect of egg-size plasticity in a hypothetical species that possesses this ability. We then ask how stickleback might differ, given their apparent lack of short-term egg-size plasticity. We also explore the direction of evolution in fresh water given the known ancestral condition.

Contemporary phenotypic evolutionary ecology emphasizes the importance of the integration of multiple traits (Pigliucci, 2003; Reynolds, 2009; Robinson and Beckerman, 2013). DeWitt and Langerhans (2004) expand on this idea by differentiating between constitutive and plastic aspects of integrated phenotypes. The effect of plasticity, and the degree to which plasticity in one trait may be linked to plasticity in other traits, depends upon the limits of plasticity in each trait (Polačik et al., 2014), and the forms of the functions relating specific trait values to fitness, modified by the effects of body size, somatic condition (Reznick and Ghalambor, 2001; Ghalambor et al., 2007), density (Leips et al., 2009) and perhaps growth rate. The increase in maternal fitness derived from a plastic response (for example, increased offspring survival or growth) should equal or exceed the expected loss because of negatively correlated traits (for example, the egg-size vs clutch-size tradeoff). This linkage has implications for the evolutionary trajectory of life-history traits, and for the evolution of plasticity in them.

If a plastic increase in egg size is cued by the environment (presumably to maintain fry fitness), then to preserve the original, presumably optimal, multivariate female life history, there must be a plastic decrease in reproductive effort ( $\sim$ fecundity) to balance the increased cost of reproduction. This is a logical adaptive tradeoff, as a plastic increase in offspring size would likely only occur when conditions (for example, food abundance) worsen. Without reducing 
reproductive effort, future survival or reproduction would be compromised, lowering lifetime fitness. In fish that produce several clutches per season, the lowered reproductive effort could be accomplished via a reduction in the number of eggs produced per clutch, to reduce per-clutch cost (an immediate tradeoff), or a reduced number of clutches to reduce 'cumulative' seasonal reproductive cost (a 'delayed' tradeoff). Which of these tactics confers greater fitness depends upon their relative costs and benefits. Increased per-clutch effort seems most likely to exact relatively immediate survival costs (Siegel et al., 1987; Rodewald and Foster, 1998; Sinervo, 1999), whereas longer-term costs may involve survival probability between reproductive season, or future reproduction costs mediated by lower growth or reduced condition (examples above) or physiological stress (Edward and Chapman, 2011; Schwartz and Bronikowski, 2011). The gain from a specified amount of expressed egg/offspring size plasticity will be determined only partly by the shape of the offspring size-fitness function (likely to be sigmoidal; Smith and Fretwell, 1974; Jorgenson et al., 2011). In this example the amount of expressible plasticity in egg size will also be constrained by the shape of the function relating the level of reproductive effort to its cost. The shape of this cost function is less clear. In addition, the total fitness gain in the above example will depend upon female size, as in organisms like stickleback both fecundity (always) and egg size (often) are positive functions of female size.

Female stickleback show a complex pattern of plasticity across the traits we examined, and as indeterminate growers the life-history traits are also strongly affected by body size (Wootton 1973a; Baker et al., 1998, 2008). A typical set of correlations among life-history traits, female size and somatic condition are shown in Figure 9. Female threespine stickleback show no clutch-to-clutch plasticity in egg size and, therefore, if ration level for females is reduced for a length of time sufficient to deplete energy capital, stickleback are unable to increase egg size to buffer potential environmental effects on their offspring. Adaptive plasticity may be expressible only by reduction in reproductive effort that, as indicated above, is probably mediated in one of (or a combination of) the three ways: (1) via a reduction in the number of follicles recruited into vitellogenesis (that is, reduced clutch size) as body size/energy content declines, (2) via a longer interclutch interval or (3) by earlier cessation of reproduction (produce fewer seasonal clutches). If fluctuations in adult ration are mirrored by reductions in fry ration (via density effects, for example; Allen et al., 2008), this means that fry fitness would also be reduced as the environment now requires a larger fry while, in addition, clutch size is also reduced-a double hit to within-season fitness. Thus, the principal fitness benefit of life-history plasticity must be survival to reproduce in a subsequent
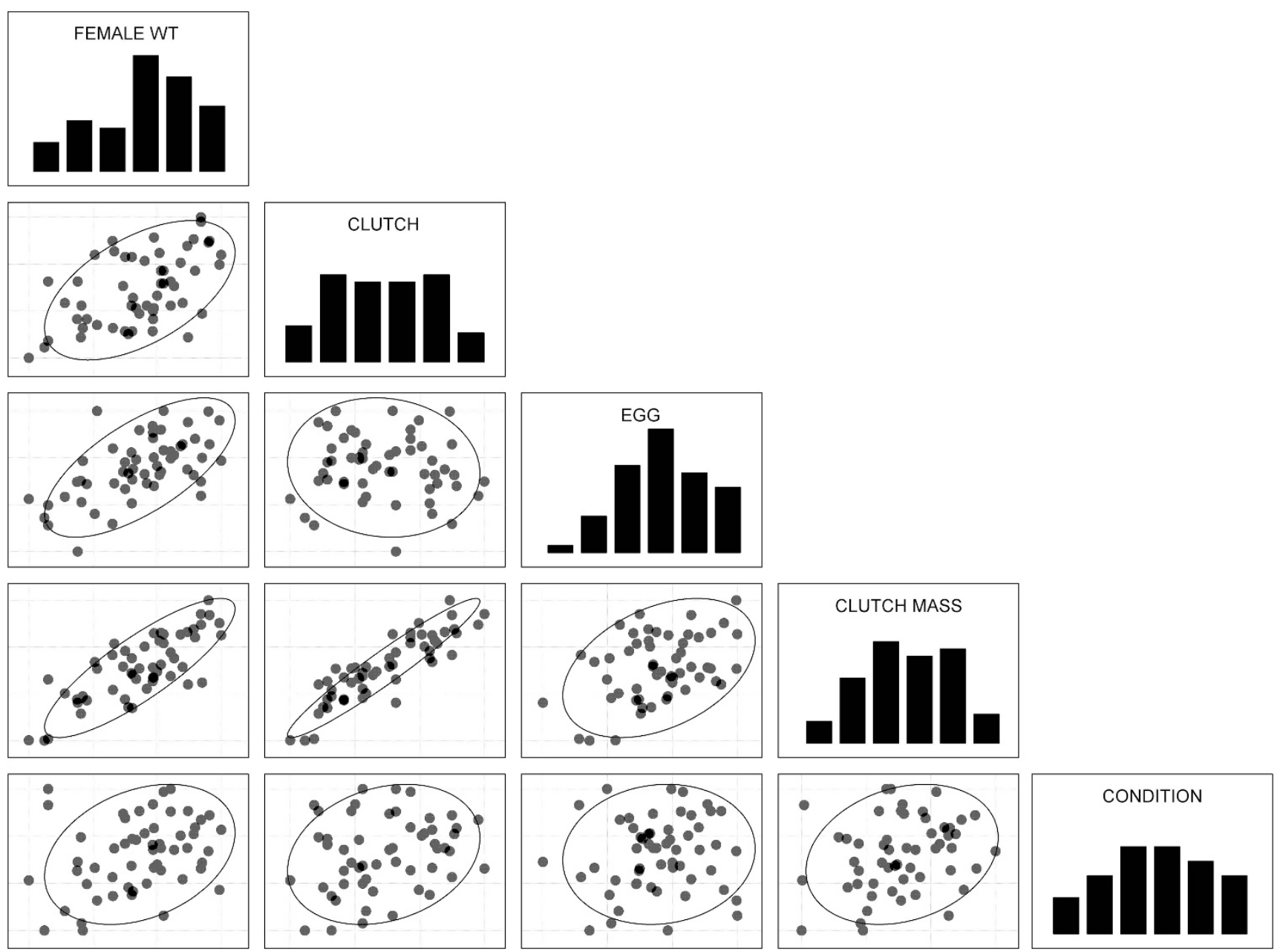

Figure 9 Matrix plot showing the relationships between female life-history traits, body mass and somatic condition in Big Beaver Lake, Alaska. The 99\% probability ellipses are plotted for each pairwise combination of traits. Correlations were based on log values for female somatic mass, clutch size, egg size and clutch mass. Condition was the residual from a regression of log somatic mass on log SL. 
year. This option is available only to populations that can spawn in multiple years, and as a result annual and longer-lived stickleback populations could evolve differently with respect to their expressible life-history plasticity.

The apparently limited within-season reproductive plasticity suggests that much of the annual variation seen in stickleback populations (Baker et al., 2008) might derive from variation in the relative abundance of different genetically based phenotypes in response to fluctuating natural selection. The oceanic stickleback that colonized freshwater habitats following the most recent glaciation, and which gave rise to the present-day adaptive radiation, appears to possess no appreciable clutch-to-clutch plasticity for egg size. As suggested earlier, this is likely because of the lack of an appropriate cue to fry conditions on the spawning grounds. As a result, freshwater populations appear to lack this plastic ability as well, and to date there is no indication that any population has evolved this ability, although admittedly few have been studied in sufficient detail. This situation appears parallel to that shown by brown trout, in that local adaptation to different streams was detected without substantial evolution of plasticity (Rogell et al., 2012).

About half of all stickleback populations we have studied in Alaska and British Columbia possess what we are calling season-to-season plasticity in egg size, expressed as a positive relationship between egg size and female size or age. The phenomenon is widespread (Roff, 1992), but a general explanation for why egg/offspring size should increase with female size/age has not yet been found, although several theoretical models (for example, Parker and Begon; Falster et al., 2008, Kindsvater and Otto, 2014) suggest some possibilities. Unfortunately, we can suggest no explanation for stickleback that fits with any of the possibilities in their models. Despite the lack of an explanation, the interesting fact is that the positive relationship is ancestral, and it appears that perhaps half of all populations no longer express it. This loss of response is almost certainly because of relaxed selection by some unknown factor, and understanding the conditions that differ between these types of populations may help to resolve the general issue, although to date this has not been attempted.

In summary, the threespine stickleback adaptive radiation has been widely used to investigate both adaptive change and phenotypic plasticity in behavioral and morphological traits. Similarly, presumably adaptive variation in life history has been documented for many populations. However, the potential for using this system to understand life-history plasticity, and to contrast it to evolutionary change, has not been widely appreciated. The widespread geographic and habitat distribution (Bell and Foster, 1994), the tremendous variation of all life-history traits (Baker et al., 2008) and the relative ease of studying stickleback in both nature and the laboratory make this species ideal for such investigations.

\section{DATA ARCHIVING}

Data available from the Dryad Digital Repository: http://dx.doi.org/ 10.5061/dryad.c69m7

\section{CONFLICT OF INTEREST}

The authors declare no conflict of interest.

\section{ACKNOWLEDGEMENTS}

First, we thank the many students from both Clark University and Tulane University who assisted with this study in the field and the laboratory. The research described here has been supported by Clark University and grants from the USA National Science Foundation (to SA Foster, JA Baker, ML Reyes and RW King) and by The Newcomb College Institute of Tulane University (to
DC Heins). Our long-term studies of stickleback in Alaska and British Columbia was also supported by annual collecting and import permits from the Alaska Department of Fish and Game, and the British Columbia Ministry of the Environment. The research complied with applicable laws and was carried out under several approved Clark University and Tulane University institutional care and use committee protocols. Three anonymous reviewers provided thought-provoking comments for improvement.

Adolph SC, Porter PP (1996). Growth, seasonality, and lizard life histories: age and size at maturity. Oikos 77: 267-278.

Ali M, Wootton RJ (1999a). Coping with resource variation: effect of constant and variable intervals between feeding on reproductive performance at first spawning of female threespined sticklebacks. J Fish Biol 55: 211-220.

Ali M, Wootton RJ (1999b). Effect of variable food levels on reproductive performance of breeding female three-spined sticklebacks. J Fish Biol 55: 1040-1053.

Allen RM, Buckley YM, Marshall DJ (2008). Offspring size plasticity in response to intraspecific competition: an adaptive maternal effect across life-history stages. Am Nat 171: 225-237.

Anderson JT (1988). A review of size dependent survival during pre-recruit stages of fish in relation to recruitment. J Northwest Atl Fish Sci 8: 55-66.

Anguilleta MJ Jr., Steury TD, Sears MW (2004). Temperature, growth rate, and body size in ectotherms: fitting pieces of a life-history puzzle. Integr Comp Biol 44: 498-509.

Arendt JD (1997). Adaptive intrinsic growth rates: an integration across taxa. Q Rev Biol 72: $149-177$.

Auer SK (2010). Phenotypic plasticity in adult life-history strategies compensates for a poor start in life in Trinidadian guppies (Poecilia reticulata). Am Nat 176: 818-829.

Baker JA, Foster SA, Heins DC, Bell MA, King RW (1998). Variation in female life-history traits among Alaskan populations of the threespine stickleback, Gasterosteus aculeatus, L. (Pisces: Gasterosteidae). Biol J Linn Soc Lond 63: 141-159.

Baker JA, Foster SA (2002). Phenotypic plasticity for life-history traits in a stream population of the threespine stickleback, Gasterosteus aculeatus L. Ecol Freshw Fish 11: 20-29.

Baker JA, Cresko WC, Heins DC, Foster SA (2005). Life-history differentiation of benthic and limnetic ecotypes in a polytypic population of threespine stickleback (Gasterosteus aculeatus). Evol Ecol Res 7: 121-131.

Baker JA, Heins DC, Foster SA, King RW (2008). An overview of life-history variation in female threespine stickleback. Behaviour 145: 579-602.

Baker JA, Räsänen K, Moore J-S, Hendry AP (2013). Genetic and plastic contributions to trait divergence between parapatric habitats: female life-history traits in threespine stickleback within the Misty Lake System. Evol Ecol Res 15: 473-487.

Barot S, Heino M, O'Brien L, Dieckmann U (2004). Long-term trend in the maturation reaction norm of two cod stocks. Ecol App/s 14: 1257-1271.

Bashey F (2006). Cross-generational environmental effects and the evolution of offspring size in the Trinidadian guppy Poecilia reticulata. Evolution 60: 348-361.

Bell MA, Foster SA (1994). Introduction to the evolutionary biology of the threespine stickleback. In: Bell MA, Foster SA (eds) The Evolutionary Biology of the Threespine Stickleback. Oxford University Press: Oxford, pp 1-27.

Berg OK, Hendry AP, Svendsen B, Bech C, Arnekleiv JV, Lohrmann A (2001). Materna provisioning of offspring and the use of those resources during ontogeny: variation within and between Atlantic Salmon families. Funct Ecol 15: 13-23.

Bernardo J (1996). The particular maternal effect of propagule size, especially egg size: patterns, models, quality of evidence and interpretations. Am Zool 36: 216-236.

Bertschy KA, Fox MG (1999). The influence of age-specific survivorship on pumpkinseed sunfish life histories. Ecology 80: 2299-2313.

Berrigan D, Koella JC (1994). The evolution of reaction norms: simple models for age and size at maturity. J Evol Biol 7: 549-566.

Boule V, FitzGerald GJ (1989). Effects of constant and fluctuating temperatures on egg production in the threespine stickleback (Gasterosteus aculeatus). Can J Zool 67: 1599-1602.

Bourdeau PE (2012). Intraspecific trait cospecialization of constitutive and inducible morphological defences in a marine snail from habitats with different predation risk $J$ Anim Ecol 81: 849-858.

Brown-Peterson NJ, Heins DC (2009). Interspawning interval of wild three-spined stickleback Gasterosteus aculeatus in Alaska. J Fish Biol 74: 2299-2312.

Brown GP, Shine R (2007). Repeatability and heritability of reproductive traits in freeranging snakes. J Evol Biol 20: 588-596.

Burd M, Read J, Sanson GD, Jaffre T (2006). Age-size plasticity for reproduction in monocarpic plants. Ecology 87: 2755-2764.

Casas JS, Pincebourde N, Mandon F, Vannier R, Poujol R, Giron D (2005). Lifetime nutrient dynamics reveal simultaneous capital and income breeding in a parasitoid. Ecology 86: 545-554

Copp GH, Fox MG (2007). Growth and life history traits of introduced pumpkinseed (Lepomis gibbosus) in Europe, and the relevance to its potential invasiveness. In: Gherardi F (ed) Biological Invaders in Inland Waters: Profiles, Distribution, and Threats vol. 2, Invading Nature-Springer Series in Invasion Ecology. Springer: Netherlands, pp 289-306.

Copp GH, Kovac V, Blacker F (2002). Differential reproductive allocation in sympatric streamdwelling sticklebacks. Gasterosteus aculeatus and Pungitius pungitius 51: 337-351. 
Crespi BJ, Teo R (2002). Comparative phylogenetic analysis of the evolution of sememparity and life history in salmonid fishes. Evolution 56: 1008-1020.

Crivelli AJ, Britton RH (1987). Life history adaptations of Gasterosteus aculeatus in a Mediterranean wetland. Environ Biol Fish 18: 109-125.

Day T, Rowe $L$ (2002). Developmental thresholds and the evolution of reaction norms for age and size at life-history transitions. Am Nat 159: 338-350.

DeWitt TJ (1998). Costs and limits of phenotypic plasticity: tests with predator-induced morphology and life history in a freshwater snail. J Evol Biol 11: 465-480.

DeWitt TJ, Sih A, Wilson DS (1998). Costs and limits of phenotypic plasticity. Trends Ecol Evol 13: 77-81.

DeWitt TJ, Scheiner S (2004). Phenotypic variation from single genotypes. In: DeWitt TJ, Scheiner SM (eds) Phenotypic Plasticity: Functional and Conceptual Approaches. Oxford University Press: New York, pp 1-9.

DeWitt TJ, Langerhans RB (2004). Integrated solutions to environmental heterogeneity: theory of multimoment reaction norms. In: DeWitt TJ, Scheiner SM (eds). Phenotypic Plasticity: Functional and Conceptual Approaches. Oxford University Press: New York, NY, USA, pp 98-111.

Donelson JM, McCormick MI, Munday PL (2008). Parental condition affects early lifehistory in a coral reef fish. J Exp Mar Biol Ecol 360: 109-116.

Duarte CM, Alcaraz M (1989). To produce many small or few large eggs: a size-independent reproductive tactic of fish. Oecologia 80: 401-404

Dufresne F, FitzGerald GJ, Lachance S (1990). Age and size-related differences in reproductive success and reproductive costs in threespine sticklebacks (Gasterosteus aculeatus). Behav Ecol 1: 140-147.

Edward DA, Chapman T (2011). Mechanisms underlying reproductive trade-offs: costs of reproduction. In: Flatt T, Heyland A (eds) Mechanisms of Life History Evolution. Oxford University Press: Oxford, pp 137-152.

Einum S, Fleming IA (2000a). Selection against late emergence and small offspring in Atlantic Salmon (Salmo salar). Evolution 54: 628-639.

Einum S, Fleming IA (2000b). Highly fecund mothers sacrifice offspring survival to maximize fitness. Nature 405: 565-567.

Evans JP, Box TM, Brooshooft P, Tatler JR, Fitzpatrick JL (2010). Females increase egg deposition in favor of large males in the rainbowfish, Melanotaenia australis. Behav Ecol 21: 465-469.

Falster DS, Moles AT, Westoby M (2008). A general model for the scaling of offspring size and adult size. Am Nat 172: 299-317.

Fletcher DA, Wootton RJ (1995). A hierarchical response to differences in ration size in the reproductive performance of female three-spined sticklebacks. J Fish Biol 46: 657-668.

Forsman A (2015). Rethinking phenotypic plasticity and its consequences for individuals, populations and species. Heredity (Edinb) 115: 276-284

Foster SA (2013). Evolutionary insights from behavioural geography: plasticity, evolution and responses to rapid environmental change. Evol Ecol Res 15: 705-731.

Foster SA, Wund MA (2011). Ancestral plasticity and adaptive evolution in the threespine stickleback radiation. In: Hallgrímsson B, Hall BK (eds) Epigenetics: Linking Genotype and Phenotype in Development and Evolution. University of California Press: Los Angeles, CA, USA, pp 317-336.

Foster SA, Scott RJ, Cresko WA (1998). Nested biological variation and speciation. Phil Trans $R$ Soc Lond B 353: 207-218.

Foster SA, Wund MA, Baker JA (2015). Evolutionary influences of plastic behavioral responses to environmental challenges in an adaptive radiation. Integr Comp Biol; e-pub ahead of print 10 July 2015.

Galloway LF, Etterson JR (2009). Plasticity to canopy shade in a monocarpic herb: withinand between-generation effects. New Phytol 182: 103-112.

Gagliano M, McCormick MI (2007). Maternal condition influences phenotypic selection on offspring. J Anim Ecol 76: 174-182.

Ghalambor CK, McKay JK, Carroll SP, Reznick DN (2007). Adaptive versus non-adaptive phenotypic plasticity and the potential for contemporary adaptation in new environments. Funct Ecol 21: 394-407.

Godfray HCJ, Partridge L, Harvey PH (1991). Clutch size. Annu Rev Ecol Syst 22: 409-429.

Grimaldi AA, Insausti P, Vasellati V, Striker GG (2005). Constitutive and plastic root traits and their role in differential tolerance to soil flooding among coexisting species of a lowland grassland. Int J Plant Sci 166: 805-813.

Gunderson DR (1997). Trade-off between reproductive effort and adult survival in oviparous and viviparous fishes. Can J Fish Aquat Sci 54: 990-998.

Gunderson DR, Dygert PH (1988). Reproductive effort as a predictor of natural mortality rate. J Cons Int Explor Mer 44: 200-209.

Hamel S, Côté SD, Gaillard J-M, Festa-Bianchet M (2009). Individual variation in reproductive costs of reproduction: high-quality females always do better. J Anim Ecol 78: 143-151.

Hamel S, Yoccoz NG, Gaillard J-M (2014). A standardized approach to estimate life history tradeoffs in evolutionary ecology. Oikos 123: 151-160.

Heins DC, Baker JA (1993). Reproductive biology of the brighteye darter, Etheostoma lynceum (Teleostei: Percidae), from the Homochitto River, Mississippi. Ichthyol Explor Fresh 4: 11-20.

Heins DC, Baker JA (2003). Reduction in egg size in natural populations of threespine stickleback infected with a cestode macroparasite. J Parasitol 89: 1-6.

Heins DC, Baker JA (2008). The stickleback-Schistocephalus host-parasite system as a model for understanding the effect of a macroparasite on host reproduction. Behaviour 145: 625-645

Henis DC, Baker JA (2014). Fecundity compensation and fecundity reduction among populations of the three-spined stickleback infected by Schistocephalus solidus in Alaska. Parasitology 141: 1088-1096.

Heins DC, Singer SS, Baker JA (1999). Virulence of the cestode Schistocephalus solidus and reproduction in infected threespine stickleback, Gasterosteus aculeatus. Can J Zool 77: 1967-1974.
Heins DC, Birden EL, Baker JA (2010). Host mortality and variability in epizootics of Schistocephalus solidus infecting the threespine stickleback Gasterosteus aculeatus. Parasitology 137: 1681-1686.

Heins DC, Barry KA, Petrauskas LA (2014). Consistency of host responses to parasitic infection in the three-spined stickleback fish infected by the diphyllobothriidean cestode Schistocephalus solidus. Biol J Linn Soc Lond 113: 958-968.

Henderson BA, Morgan GE (2002). Maturation of walleye by age, size and surplus energy. J Fish Biol 61: 999-1011.

Hohenlohe PA, Bassham S, Currey M, Cresko WA (2012). Extensive linkage disequilibrium and parallel adaptive divergence across threespine stickleback genomes. Philos Trans $R$ Soc B Biol Sci 367: 395-408.

Hooker LJ (1988). Sexual size dimorphism in two populations of threespine stickleback (Gasterosteus aculeatus): female body size and seasonal fecundity in a multiple spawning species. Unpublished M.Sc. Thesis, University of British Columbia, Vancouver, British Columbia, Canada.

Houde ED (1987). Fish early life dynamics and recruitment variability. Am Fish Soc Symp Ser 2 17-29.

Houston Al, Stephens PA, Boyd IL, Harding KC, McNamara JM (2007). Capital or income breeding? A theoretical model of female reproductive strategies. Behav Ecol 18: 241-250.

Hutchings JA (1999). Influence of growth and survival costs of reproduction on Atlantic cod, Gadus morhua, population growth rate. Can J Fish Aquat Sci 56: 1612-1623.

Hutchings JA, Jones MEB (2008). Life history variation and growth rate thresholds for maturity in Atlantic salmon, Salmo salar. Can J Fish Aquat Sci 55: 22-47.

Inness CLW, Metcalfe NB (2008). The impact of dietary restriction, intermittent feeding and compensatory growth on reproductive investment and lifespan in a short-lived fish. Proc R Soc B 275: 1703-1708.

Jorgensen C, Auer SK, Reznick DN (2011). A model for optimal offspring size in fish, including live-bearing and parental effects. Am Nat 117: E119-E135.

Karve AD, von Hippel FA, Baker JA. (2013). Female life-history traits in a species pair of threespine stickleback in Mud Lake, Alaska. Evol Ecol Res 15: 171-187.

Kennedy J, Witthames PR, Nash RDM (2007). The concept of fecundity regulation in plaice (Pleuronectes plastessa) tested on three Irish Sea spawning populations. Can J Fish Aquat Sci 64: 587-601.

Kennedy J, Witthames PR, Nash RDM, Fox CJ (2008). Is fecundity in plaice (Pleuronectes platessa L.) down-regulated in response to reduced food intake during autumn? J Fish Biol 72: 78-92.

Kennedy J, Gundersen AC, Boje J (2009). When to count your eggs: is fecundity in Greenland halibut (Reinhardtius hippoglossoides W.) down-regulated? Fish Res 100: 260-265.

Kindsvater HK, Otto SP (2014). The evolution of offspring size across life-history Stages. Am Nat 184: 543-555.

Kingsolver JG, Hoekstra HE, Hoekstra JM, Berrigan D, Vignieri SN, Hill C et al. (2001). The strength of phenotypic selection in natural populations. Am Nat 157: 245-261.

Kinnison MT, Unwin MJ, Hendry AP, Quinn TP (2001). Migratory costs and the evolution of egg size and number in introduced and indigenous salmon populations. Evolution 55: 1656-1667.

Klemetsen A, Amundsen PA, Dempson JB, Jonsson B, Jonsson N, O'Connell MF et al. (2003). Atlantic salmon Salmo salar L., brown trout Salmo trutta L. and Arctic charr Salvelinus alpinus (L.): a review of aspects of their life histories. Ecol Freshw Fish 12 : $1-59$.

Koivula M, Koskela E, Mappes T, Oksanen TA (2003). Cost of reproduction in the wild: manipulation of reproductive effort in the bank vole. Ecology 84: 398-405.

Kolm N (2001). Females produce larger eggs for large males in a paternal mouthbrooding fish. Proc $R$ Soc Lond B 268: 2229-2234.

Kuparinen A, Hardie DC, Hutchings JA (2011). Evolutionary and ecological feedbacks of the survival cost of reproduction. Evol App/ 5: 245-255.

Lancaster LT, McAdam AG, Sinervo B (2010). Maternal adjustment of egg size organizes alternative escape behaviors, promoting adaptive phenotypic integration. Evolution 64: 1607-1621.

Lee W-S, Monaghan P, Metcalfe NB (2012). The pattern of early growth trajectories affects adult breeding performance. Ecology 93: 902-912

Leips J, Richardson JLM, Rodd FH, Travis J (2009). Adaptive maternal adjustments of offspring size in response to conspecific density in two populations of the least killifish, Heterandria formosa. Evolution 63: 1341-1347

Lourdais O, Bonnet X, Shine R, Denardo D, Naulleau G, Guillon M (2002). Capital-breeding and reproductive effort in a variable environment: a longitudinal study of a viviparous snake. J Anim Ecol 71: 470-479.

Madsen T, Shine R (1999). The adjustment of reproductive threshold to prey abundance in a capital breeder. J Anim Ecol 68: 571-580.

Marshall DJ, Uller T (2007). When is a maternal effect adaptive? Oikos 116: 1957-1963. Marty L, Dieckmann U, Rochet M-J, Ernande B (2011). Impact of environmental covariation in growth and mortality on evolving maturation reaction norms. Am Nat 177: E98-E118.

McKinnon JS, Rundle HD (2002). Speciation in nature: the threespine stickleback model systems. Trends Ecol Evol 17: 480-488.

McPhail J (1977). Inherited interpopulation differences in size at first reproduction in threespine stickleback, Gasterosteus aculeatus L. Heredity 38: 53-60.

Merila J, Laurila A, Laugen AT, Rasanen K, Pahkala M (2000). Plasticity in age and size at metamorphosis in Rana temporaria - comparison of high and low latitude populations. Ecography 23: 457-465.

Messler A, Wund MA, Baker JA, Foster SA (2007). The effects of relaxed and reversed selection by predators on the antipredator behavior of the threespine stickleback, Gasterosteus aculeatus. Ethology 113: 953-963.

Metcalfe NB, Monaghan P (2003). Growth versus lifespan: perspectives from evolutionary ecology. Exp Gerontol 38: 935-940. 
Morgan MJ (2004). The relationship between fish condition and the probability of being mature in American plaice (Hippoglossoides platessoides). ICES J Mar Sci 61: 64-70.

Moore PJ, Attisano A (2011). Oosorption in response to poor food: complexity in the tradeoff between reproduction and survival. Ecol Evol 1: 37-45.

Moran NA (1992). The evolutionary maintenance of alternative phenotypes. Am Nat 139 971-989.

Morita K, Fukuwaka M (2006). Does size matter most? The effect of growth history on probabilistic reaction norm for salmon maturation. Evolution 60: 1516-1521.

Mousseau TA, Roff DA (1987). Natural selection and the heritability of fitness components. Heredity 59: 181-197.

Mousseau TA, Fox CW (1998). The adaptive significance of maternal effects. Trends Ecol Evol 13: 403-407.

Narver DW (1969). Phenotypic variation in threespine sticklebacks (Gasterosteus aculeatus) of the Chignik River System, Alaska. J Fish Res Board Can 26: 405-412.

Nylin S, Gotthard K (1998). Plasticity in life-history traits. Annu Rev Entomol 43: 63-83.

Oravec TJ, Reimchen TE (2013). Divergent reproductive life histories in Haida Gwail stickleback (Gasterosteus spp.). Can J Zool 91: 17-24.

Padilla DK, Adolph SC (1996). Plastic inducible morphologies are not always adaptive: the importance of time delays in a stochastic environment. Evol Ecol 10: 105-117.

Parker GA, Begon M (1986). Optimal egg size and clutch size: effects of environment and maternal phenotype. Am Nat 128: 573-592.

Picard P Jr, Dodson JL, FitzGerald GJ (1990). Habitat segregation among the age groups of Gasterosteus aculeatus (Pisces: Gasterosteidae) in the middle St. Lawrence estuary, Canada. Can J Zool 68: 1202-1208.

Pampoulie C, Bouchereau JL, Rosecchi E, Poizat G, Crivelli AJ (2000). Annual variations in the reproductive traits of Pomatoschistus microps in a Mediterranean lagoon undergoing environmental changes: evidence of phenotypic plasticity. J Fish Biol 57: 1441-1452.

Perez KO, Munch SB (2010). Extreme selection on size in the early lives of fish. Evolution 64: 2450-2457.

Pigliucci M (2003). Phenotypic integration: studying the ecology and evolution of complex phenotypes. Ecol Lett 6: 265-272.

Poizat G, Rosecchi E, Crivelli AJ (1999). Empirical evidence of a trade-off between reproductive effort and expectation of future reproduction in female three-spined sticklebacks. Proc $R$ Soc Lond Ser B Biol Sci 266: 1543-1548.

Polačik M, Blažek R, Řežucha R, Vrtilek M, Terzibasi Tozzini E, Reichard M (2014). Alternative intrapopulation life-history strategies and their trade-offs in an African annual fish. J Evol Biol 27: 854-865.

Reger RD, Pinney DS (1996). Late Wisconsin glaciation of the Cook Inlet Region with emphasis on the Kenai lowland and implications for early peopling. In: David NY, Davids WE (eds) Adventures Through Time: Readings in the Anthropology of Cook Inlet, Alaska. Cook Inlet Historical Society: Anchorage, pp 15-35.

Relyea RA (2002). Costs of phenotypic plasticity. Am Nat 159: 272-282.

Reznick D, Yang AP (1993). The influence of fluctuating resources on life history: patterns of allocation and plasticity in female guppies. Ecology 74: 2011-2019.

Reznick DA, Bryga H, Endler JA (1990). Experimentally induced life-history evolution in a natural population. Nature 346: 357-359.

Reznick D, Nunney L, Tessier A (2000). Big houses, big cars, superfleas and the costs of reproduction. Trends Ecol Evol 15: 421-425.

Reznick DN, Ghalambor CK (2001). The population ecology of contemporary adaptations: what empirical studies reveal about the conditions that promote adaptive evolution. Genetica 112-113: 183-198.

Reynolds RJ, Dudash MR, Fenster CB (2009). Multiyear study of multivariate linear and nonlinear phenotypic selection on floral traits of hummingbird-pollinated Silene virginica. Evolution 64: 358-369.

Rideout RM, Rose GA, Burton MPM (2005). Skipped spawning in female iteroparous fishes. Fish Fish 6: 50-72.

Robinson M, Beckerman AP (2013). Quantifying multivariate plasticity: genetic variation in resource acquisition drives plasticity in resource allocation to components of life history. Ecol Lett 16: 281-290.

Rodd FH, Reznick DN, Sokolowski MB (1997). Phenotypic plasticity in the life history traits of guppies: responses to social environment. Ecology 78: 419-433.

Rodewald AD, Foster SA (1998). Effects of gravidity on habitat use and antipredator behavior in three-spined sticklebacks. J Fish Biol 52: 973-984.

Roff DA (1992). The Evolution of Life Histories: Theory and Analysis. Chapman and Hall: New York.

Roff D (2000). Trade-offs between growth and reproduction: an analysis of the quantitative genetic evidence. J Evol Biol 13: 434-445.

Roff DA (2002). Life History Evolution. Sinauer Associates, Inc.: Sunderland, MA

Roff DA, Tucker J, Stirling G, Fairbairn DJ (1999). The evolution of threshold traits: effects of selection on fecundity and correlated response in wing dimorphism in the sand cricket. J Evol Biol 12: 535-546.

Rogell B, Dannewitz J, Palm S, Petersson E, Dahl J, Prestegaard T et al. (2012). Strong divergence in trait means but not in plasticity across hatchery and wild populations of sea-run brown trout Salmo trutta. Molecular Ecology 21: 2963-2976.

Rundle HD, Nagel L, Boughman JW, Schluter D (2000). Natural selection and paralle speciation in sympatric sticklebacks. Science 287: 306-308.

Saito T, Nakano S (1999). Reproductive-timing-dependent alternation of offspring life histories in female threespine sticklebacks. Can J Zool 77: 1314-1321.

Schwartz TS, Bronikowski AM (2011). Molecular stress pathways and the evolution of life histories in reptiles. In: Flatt T, Heyland A (eds) Mechanisms of Life History Evolution. Oxford University Press: Oxford, pp 193-209.

Schluter D (2000). The Ecology of Adaptive Radiation. Oxford University Press: Oxford.
Segers FH, Taborsky B (2011). Egg size and food abundance interactively affect juvenile growth and behavior. Funct Ecol 25: 166-176.

Shine R (1980). "Costs" of reproduction in reptiles. Oecologia 46: 92-100.

Siegel RA, Huggins MM, Ford NB (1987). Reduction in locomotor ability as a cost of reproduction in snakes. Oecologia 73 : 481-485.

Simons AM (2008). One big, and many small reasons that direct selection on offspring number is still open for discussion. J Evol Biol 21: 642-645.

Sinervo B (1999). Mechanistic analysis of natural selection and a refinement of Lack's and Williams's principles. Am Nat 154: S26-S42.

Skjæraasen JE, Nash RDM, Korsbrekke K, Fonn M, Nilsen T, Kennedy J et al. (2012). Frequent skipped spawning in the world's largest cod population. Proc Natl Acad Sci USA 109: 8995-8999.

Smith CC, Fretwell SD (1974). The optimal balance between size and number of offspring. Am Nat 108: 499-506.

Snell-Rood EC (2013). An overview of the evolutionary causes and consequences of behavioural plasticity. Anim Behav 85: 1004-1011.

Snyder RJ (1991). Quantitative genetic analysis of life histories in two freshwater populations of threespine stickleback. Copeia 1991: 526-529.

Snyder RJ, Dingle H (1989). Adaptive, genetically based differences in life history between estuary and freshwater threespine sticklebacks (Gasterosteus aculeatus L.). Can J Zool 67: 2448-2454.

Stearns SC (1989). The evolutionary significance of phenotypic plasticity. Bioscience 39 436-445.

Sokolowska E, Kulczykowska E (2006). Annual reproductive cycle in two free living populations of three-spined stickleback (Gasterosteus aculeatus L.): patterns of ovarian and testicular development. Oceanologia 48: 103-124.

Stephens PA, Boyd L, McNamara JM, Houston AI (2009). Capital breeding and income breeding: their meaning, measurement, and worth. Ecology 90: 2057-2067.

Su G-S, Liljedahl LE, Gall GAE (1997). Effects of inbreeding on growth and reproductive traits in rainbow trout (Oncorhynchus mykiss). Aquaculture 142 139-148.

Teder T, Vellau H, Tammaru T (2014). Age and size at maturity: a quantitative review of diet-induced reaction norms in insects. Evolution 68: 3217-3228.

Thorpe JE (2007). Maturation responses of salmonids to changing developmental opportunities. Mar Ecol Prog Ser 335: 285-288.

Trippel EA, Harvey HH (1989). Missing opportunities to reproduce: an energy dependent or fecundity gaining strategy in white sucker (Catostomus commersonı)? Can J Zool 67: 2180-2188.

Tsiklris AC, Antonopoulou E, Stergiou K (2007). A phenotypic trade-off between previous growth and present fecundity in round sardinella Sardinella aurita. Popul Ecol 49 221-227

Vrtilek M, Reichard M (2014). Highly plastic allocation to growth and reproduction in females of an African annual fish. Ecol Freshw Fish; doi:10.1111/eff.12175.

Vitousek MN, Mitchell MA, Romero LM, Awerman J, Wikelski M (2010). To breed or not to breed: physiological correlates of reproductive status in a facultatively biennial iguanid. Horm Behav 57: 140-146.

Wallace RA, Selman K (1979). Physiological aspects of oogenesis in two species of sticklebacks, Gasterosteus aculeatus L. and Apeltes quadracus (Mitchill). J Fish Biol 14: 551-564.

Weeks SC, Quattro JM (1991). Life-history plasticity under resource stress in a clonal fish (Poeciliidae: Poeciliopsis). J Fish Biol 39: 485-494.

Winkler DW, Wallin K (1987). Offspring size and number: a life history model linking effort per offspring and total effort. Am Nat 129: 708-720.

Wisenden BD (1993). Female convict cichlids adjust gonadal investment in current reproduction in response to relative risk of brood predation. Can J Zool 71: 251-256.

Wootton RJ (1973a). Fecundity of the three-spined stickleback, Gasterosteus aculeatus (L.). J Fish Biol 5: 683-688.

Wootton RJ (1973b). The effect of size of food ration on egg production in the female threespined stickleback, Gasterosteus aculeatus L. J Fish Biol 5: 89-96.

Wootton RJ (1977). Effect of food limitation during the breeding season on the size, body components and egg production of female sticklebacks (Gasterosteus aculeatus). Anim Ecol 46: 823-834.

Wootton RJ (1994). Energy allocation in the threespinne stickleback In: Bell MA, Foster SA (eds), The Evolutionary Biology of the Threespine Stickleback. Oxford University Press: Oxford, pp 114-143.

Wootton RJ, Allen JRM, Cole SJ (1980). Energetics of the annual reproductive cycle in female sticklebacks, Gasterosteus aculeatus L. J Fish Biol 17: 387-394.

Wootton RJ, Evans GW (1976). Cost of egg production in the three-spined stickleback (Gasterosteus aculeatus L.). J Fish Biol 8: 385-395.

Wootton RJ, Fletcher DA (2009). Effect of spawning number and ration on reproductive performance of the batch-spawning three-spined stickleback Gasterosteus aculeatus. J Fish Biol 75: 618-629.

Wootton RJ, Evans GW, Mills L (1978). Annual cycle in female three-spined sticklebacks (Gasterosteus aculeatus L.) from an upland and lowland population. J Fish Biol 12 331-343.

Wund MA, Baker JA, Clancy B, Golub J, Foster SA (2008). A test of the 'flexible stem' model of evolution: ancestral plasticity, genetic accommodation, and morphological divergence in the threespine stickleback radiation. Am Nat 172: 449-462.

Wund MA, Valena S, Wood S, Baker JA (2012). Ancestral plasticity and allometry in threespine stickleback fish reveal phenotypes associated with derived, freshwater ecotypes. Biol J Linn Soc USA 105: 573-583. 